\section{Are Contemporary Central Banks Transparent About Economic Models and Objectives and What Difference Does It Make?}

\author{
Alex Cukierman
}

\section{INTRODUCTION}

$\triangle$ uthority over monetary policy has increasingly been delegated to central banks with substantially higher levels of independence than in the past. This worldwide trend has propelled the twin issues of accountability and transparency to the forefront of the debate on monetary institutions. The current debate is particularly intense on the European side of the Atlantic where the formation of a European Central Bank (ECB) facing 12 different fiscal authorities and different types of labor markets has transformed those previously mainly academic questions into practical policy issues.

There is nowadays a good deal of consensus about the objectives and desirable organization of monetary policymaking institutions. In particular, there is widespread consensus that the main objective of monetary policy should be price stability, that the central bank (CB) should have the freedom to set the interest rate without political interference, and that the objectives and the procedures followed by the CB should be reasonably transparent. The insistence on transparency is motivated by the desire to ultimately make the $\mathrm{CB}$ accountable to the general public either directly or through the intermediation of elected officials. But once those general principles are translated into operational

Alex Cukierman is a professor of economics at the Berglas School of Economics, Tel-Aviv University, and a research fellow at the Center for Economic Research, Tilburg University, and CEPR. Previous versions of this paper were presented at the October 2000 Bundesbank/CFS conference Transparency in Monetary Policy and at the September 2001 CEPR/ESI conference Old Age, New Economy and Central Banking at the Bank of Finland. The author thanks Matthew Canzoneri, Jordi Gali, Petra Geraats, Arie Kapteyn, and Carl Walsh for useful discussions.

(c) 2002, The Federal Reserve Bank of St. Louis. guidelines, some differences appear. The consensus about transparency is most fragile to the introduction of practical guidelines, as illustrated by a recent interchange between Buiter (1999) and Issing (1999). Buiter's position largely reflects what I have called elsewhere the (new) Bank of England (BE) approach, and Issing's position reflects the approach of the ECB, which has been largely shaped by the philosophy of the Bundesbank (BB) during the last several decades. ${ }^{1}$

Both approaches agree on the principle that a $\mathrm{CB}$ should be transparent and accountable but differ on the means to achieve those goals. The most vocal disagreements have been about the early publication of $\mathrm{CB}$ forecasts and the voting record of individual monetary policy council members. The BE approach is in favor of early release of this information, while the $\mathrm{BB}$ approach is against it. Those differences partly reflect the $\mathrm{BB}$ view that there should be "collective responsibility" at the $\mathrm{CB}$, while the $\mathrm{BE}$ approach puts relatively more emphasis on the accountability of individual council members. They also reflect the fact that since the second half of the 1990s countries such as the United Kingdom and Sweden have put in place an explicit mechanism of inflation targeting in conjunction with a numerically specified inflation target that is decided upon by government. ${ }^{2}$ In such systems the early publication of $\mathrm{CB}$ forecasts is believed to be an essential element of accountability because it enables the principal (government) to judge whether ex post deviations from the target were due to poor performance by the agent (the $\mathrm{CB}$ ) or to unanticipated economic shocks. The colorful debate about the publication of forecasts and CB votes overshadowed two possibly more fundamental areas in which most (perhaps even all) existing central banks are rather opaque. One concerns the economic model, or models, used in making policy decisions, and the other concerns the operational objectives of the CB.

This paper focuses on those issues. It has two main parts. The first evaluates the degree of transparency about the economic models used by con-

\footnotetext{
1 A fuller discussion of the differences between those two approaches regarding the practical implementation of transparency and other issues appears in the concluding section of Cukierman (2001). See also de Haan and Eijffinger (2000) for an appraisal of the Buiter-Issing interchange.

2 Some other countries with explicit inflation targeting systems are New Zealand, Canada, Finland, Australia, and Spain. In almost all cases the final formal authority to set the target resides with government. By contrast, in the case of the $\mathrm{BB}$ and the $\mathrm{ECB}$, the target is chosen by the $\mathrm{CB}$.
} 
temporary central banks and about their objective functions. It argues that, in spite of the recently acknowledged importance of transparency (particularly in some inflation-targeting countries), there is substantial haziness about the economic models used by CBs to generate forecasts as well as about their objective function. Some of this haziness is due to the absence of clear knowledge about the "true" model of the economy and some is due to the attempt of policymakers to hedge their positions in the face of model and of political uncertainties.

The second part of the paper examines whether haziness about objectives matters for credibility when monetary policymakers are more sensitive to negative than to positive output gaps. The initial motivation for this exercise is the following statement from Blinder (1998, pp. 19-20), made shortly after his resignation from the office of Vice Chairman of the Fed: "In most situations the CB will take far more political heat when it tightens preemptively to avoid higher inflation than when it eases preemptively to avoid higher unemployment."

A fuller description of the second part of the paper is provided after the following recent literature review.

Since the early 1980s the dominant academic paradigm for conceptualizing the positive and sustained inflation rates experienced by most countries during the twentieth century has been the KydlandPrescott (1977) and Barro-Gordon (1983) framework (henceforth KPBG). This view includes an inflation bias that is due to the fact that, owing to tax and/or other labor market imperfections, the natural level of employment is lower than the level targeted by policymakers. This induces policymakers to try to stimulate employment by means of inflationary surprises. Because the public anticipates such behavior, it adjusts nominal wages (and other) contracts accordingly, which leads to an equilibrium in which inflation has a positive bias but output remains at the natural level.

Recently two central bankers with strong academic backgrounds have expressed the view that decisionmakers in their respective CBs are not trying to maintain employment above its natural level and conclude, therefore, that the KPBG bias story is not applicable to their respective $\mathrm{CBs} .^{3}$ In particular, Blinder (1998, p. 43) argues that policymakers at the Fed do not try to systematically maintain employment above the natural level. As a matter of fact, when in office, he personally felt duty bound to conduct monetary policy so as to hit the natural rate. In a similar vein, while recently summarizing the U.K. experience with inflation targeting, John Vickers (1998, p. 369) expressed the following view: "There is a large literature on inflation bias but it simply is not applicable to the MPC. We have no desire to spring inflation surprises to try to bump output above its natural rate (wherever that may be)."

Coming from a former Fed's vice chairman and from an executive director and chief economist at the $\mathrm{BE}$, such introspective statements certainly deserve serious consideration, not the least because acceptance of this view carries with it the important implication that the credibility problem of monetary policy is a thing of the past. ${ }^{4}$

In parallel, recent inflation targeters such as the (reborn with instrument independence since 1997) BE acknowledge that, although their primary objective is price stability, they are also averse to excessive short-run fluctuations of actual output around potential or natural output. Hence, they attempt to achieve the inflation target on average rather than in each period. In Mervyn King's words, they are not "inflation nutters" (e.g., see King, 1997). For example, if an adverse supply shock pushes inflation above target for some time, they do not seek to put inflation back on target immediately because of the associated excessive fluctuations this would create in the output gap.

Svensson (1997) refers, somewhat more neutrally, to such a bank as a "flexible inflation targeter" and to King's "inflation nutter" as a "strict inflation targeter." Recent inflation targeters such as the United Kingdom, New Zealand, Canada, and Sweden have been rather transparent about the fact that they are flexible rather than strict inflation targeters. In terms of the familiar quadratic loss function used by KPBG and much of the ensuing literature, this means that, although they do not try to maintain output above its natural level, their loss function assigns a positive weight also to deviations of output from its potential level. I shall refer to the relative weight assigned to deviations of output from target in comparison with deviations of inflation from

\footnotetext{
3 McCallum $(1995,1997)$ expresses a similar view.

4 The views expressed by Blinder and Vickers are not inconsistent with the existence of a KPBG inflationary bias prior to the 1990s, provided that policymakers, at the time, believed in a stable tradeoff between inflation and economic activity. As the idea of no tradeoff percolated through policymaking circles during the 1990s, policymakers, realizing the futility of attempting to maintain output above its natural level, settled for the natural rate. Sargent (1999) models this process using least-squares learning about the slope of the long-run Phillips curve.
} 
target as the "flexibility parameter" and denote it by $A$.

In any precise characterization of optimal policy in such a context, $A$ is obviously an important determinant of the speed with which policy seeks to put inflation back on target following adverse shock realizations. The larger is $A$, the larger is the "flexibility" allowed in returning to the inflation target following a shock. Hence, along the optimal policy plan of a flexible inflation targeter, the parameter $A$ determines the period-by-period deviations of inflation from its target. In spite of its obvious importance and of their insistence on transparency, recent inflation targeters have been rather hazy about the magnitude of the flexibility parameter. This is recognized by Vickers (1998, p. 370) who candidly writes, "The MPC remit is silent on this parameter of the loss function, but optimal policy is arguably not too sensitive to its value within a reasonable range." 5

While most explicit inflation targeters openly admit that they are of the "flexible" variety, that was not usually the case with the BB when it was in charge of German monetary policy, nor is it currently the case with it successor - the ECB. In view of the strong and unequivocal priority given to price stability in the charter of those banks, their officials probably prefer to view and to project to the public an image of the bank as a strict, rather than a flexible, inflation targeter. But evidence presented in Clarida and Gertler (1997) is consistent with the view that the actual policy of the BB did not significantly differ from that of a flexible inflation targeter. Thus, there seems to be substantial haziness about the parameter $A$ among both explicit and implicit inflation targeters.

The second part of the paper takes the statements of Vickers (1998) and of Blinder (1998) (that the output target of $\mathrm{BE}$ and Fed policymakers is the natural level) at face value and examines the consequences of flexible inflation targeting and of haziness about the parameter $A$ for credibility in the presence of asymmetric objectives. Besides the statement by Blinder hinting at an asymmetry in the objectives of the U.S. political establishment, this exercise is motivated by the following considerations.

Cukierman (2000a) shows that, with a Lucastype transmission mechanism, uncertainty about the future state of the economy and asymmetries in the output gap segment of the CB loss function, there will be an inflation bias even if the $\mathrm{CB}$ targets the normal level of output. This framework implies that there should be a positive association between the variability of economic activity over the cycle and the magnitude of the inflation bias. Preliminary cross-sectional evidence in Gerlach (2000) supports this implication. ${ }^{6}$ Last but not least, the quadratic objective function originally postulated by KPBG carries the rather unintuitive implication that, given inflation, an upward deviation of employment from its desire level is as costly as a downward deviation of the same size. It is hard to see why policymakers, or social planners for that matter, would object, given inflation, to a positive output gap. As a matter of fact, it's quite likely that, in the range of positive output gaps, the quadratic function was postulated mainly for analytical convenience rather than for its descriptive realism. ${ }^{7}$

Because there is substantial uncertainty about the correct model of the economy, the consequences of asymmetric objectives are examined also for an economy with a New Keynesian transmission mechanism of the type recently reviewed by Clarida, Gali, and Gertler (1999). In this case there is an inflation bias that has two distinct origins. One of those arises, as in the case of an expectations-augmented Phillips curve, due to the interaction of asymmetries in the output gap segment of the loss function with uncertainty about the future state of the economy. Thus, flexible inflation targeting in conjunction with asymmetric output gap objectives leads to credibility problems even when policymakers target the average natural level. Furthermore, contrary to conventional wisdom (with an expectations-augmented Phillips curve), this bias is an increasing function of the extent to which the CB is "flexible" in targeting inflation as measured by the parameter $A$. Because this is precisely the parameter about which contemporary CBs tend to be hazy, it follows that there is also uncertainty about the size of the bias.

The additional inflationary tendency that arises in the New Keynesian framework is related to the fact that, because prices are sticky, policymakers

5 The qualifier refers to work by Bean (2000) and Batini and Haldane (1999), who claim that for recent structural parameters of the United Kingdom the optimal policy of a flexible inflation targeter is insensitive to the precise value of $A$.

6 In addition, Ruge-Murcia (2001) provides individual time-series evidence for several countries. His evidence supports the existence of asymmetries in CB losses from deviations of unemployment from its natural level for France and the United States but not for the United Kingdom and Japan.

7 The quadratic function does not admit the possibility that policymakers might have precautionary demands for expansions and for price stability. A formulation of policymakers' objective functions that allows for both possibilities appears in Cukierman and Muscatelli (2002). 
face a long-run tradeoff within some range between average inflation and the average output gap. Policymakers with asymmetric losses from positive and negative output gaps choose a point along this tradeoff that is characterized by both positive average inflation and a positive average output gap. ${ }^{8}$

Section II documents existing haziness about the economic models used by decisionmakers in CBs and about the level of output that they target. It is argued that, while a large part of this haziness is due to lack of clear consensus about the transmission mechanism within the economic profession itself, this state of affairs leaves quite a bit of discretion to CBs and opens the door for strategic use of information. Section III examines the extent to which contemporary CBs are transparent about their objectives and concludes that here, too, there is quite a bit of haziness, particularly among the new "flexible inflation targeters." It then reviews recent theoretical arguments and empirical work that support the hypothesis that at least some CBs have different attitudes about positive and negative output gaps.

Section IV shows, for a Lucas-type transmission mechanism, that, in the presence of such asymmetries and uncertainty about the upcoming state of the economy, policymakers "hedge" their position on the side of expansion to reduce the likelihood of surprise recessions. This behavior is shown to induce an inflationary bias even when the policymakers' output target is potential output. Section V first shows that a similar mechanism operates also in sticky price, New Keynesian models of the economy. But, because policymakers can control the real rate of interest in such frameworks, asymmetric preferences lead to an additional inflationary tendency that is associated with average positive real effects on the output gap.

\section{HAZINESS ABOUT THE ECONOMIC MODEL USED FOR MAKING POLICY DECISIONS}

Practically all CBs are rather noncommittal about the economic model or models they use in making policy decisions. Admittedly, many of the major CBs have at least one big econometric model of the economy in store. But the forecasts generated by such models are only one of many inputs used in formulating policy. Decisionmakers at major CBs have access to a multitude of alternative "models" and information. The aggregation of this information by each board member and the further aggregation of the position of each board member into a collective decision is a rather complex process; a full description of this would require very detailed tracking of the thought process of each board member as well as of the interaction among the board members. Vickers (1998, p. 370) candidly admits that there are serious limits to how much of this process can be put in the public domain?: "While transparency - inflation reports, MPC minutes, Treasury Committee hearings and so onincreases what is in the public domain (desirably in my view), there is surely information relevant for policy-making that is simply incapable of being put in the public domain."

A substantial part of this ambiguity is caused in the first place by the absence of consensus within the economic profession about the correct model of the economy. In the absence of consensus, a "reasonable" central banker is likely to hedge his position by intuitively assigning nonnegative weights to alternative conceptions of the economy. This complicates the decisionmaking process of central bankers, makes them vulnerable to ex post criticism, but also leaves them substantially more discretion than they would have otherwise. As a matter of fact, current economic literature entertains several conceptually different views of the transmission process of monetary policy even before taking into account differing views about length of lags, parameter magnitudes, and functional form within a given broad conception of the transmission mechanism.

This section illustrates some of this conceptual variety by briefly reviewing and contrasting three well-known alternative conceptions of the transmission process of monetary policy used in the current economic literature. One is a monetarist Lucas-type expectations-augmented Phillips curve and the other two are neo-Keynesian in spirit in that both rely on staggered nominal price setting in conjunction with costs of price adjustment. In both variants the $\mathrm{CB}$ is able to influence the real rate by means of the nominal rate of interest because the price level is temporarily sticky. In the first version, current prices are fully backward looking in that current pricing decisions depend only on predetermined past prices. In the second version, they are fully

\footnotetext{
8 I refer to this second mechanism as a "tendency" rather than a "bias" because it is associated with some gain in the average value of output.

9 Even if all those details could be put in the public domain, it is unlikely that, because of cognitive limitations, the bulk of the (largely nonprofessional) public would absorb and digest them accurately. A fuller discussion of those and related issues appears in Winkler (2000).
} 
forward looking in that current pricing decisions depend on expected future inflation rather than on past pricing decisions. ${ }^{10}$

\section{A Monetarist Lucas-Type Transmission Mechanism (Model 1)}

This transmission mechanism is the one most frequently used in models of endogenous monetary policy. The main idea is that monetary policy has real effects only to the extent that it creates unexpected inflation. In particular, the deviation of output from its natural level is an increasing function of unexpected inflation. Formally,

$$
y_{t} \equiv Y_{t}-Y_{n t}=\alpha\left(\pi_{t}-E_{t} \pi_{t}\right), \alpha>0,
$$

where $Y$ and $Y_{n}$ are actual and natural output, $\pi$ is the rate of inflation, $E \pi$ is the (rational) expectation of that rate of inflation when output decisions are made, and $t$ is a time index. The instrument of monetary policy is not modeled explicitly, but it is assumed, at least implicitly, that the monetary authority can set its instrument (the money supply or the interest rate) so as to bring about the inflation rate that it desires. Hence, from a formal point of view the "instrument" of the monetary authority here is the rate of inflation. ${ }^{11}$ Equation (1) is also known as an expectations-augmented Phillips curve. In its starkest monetarist interpretation, prices and wages are fully flexible and monetary policy has real effects only when inflation is not currently fully perceived. In the presence of nominal wage contracts, which are preset one period in advance on the basis of expected future inflation, there are real effects when there are deviations between the rate of inflation that had been expected at contracting time and the subsequent realization of inflation. In this variant, $E_{t} \pi_{t}$ is replaced by $E_{t-1} \pi_{t} \cdot{ }^{12}$

\section{A Neo-Keynesian Transmission Mechanism with Backward-Looking Pricing (Model 2)}

In this framework, the current output gap, normally defined as the deviation of actual from potential output, depends on the lagged real interest rate and on its own lagged value. Current inflation is positively related to the lagged value of the output gap and to its own lagged value. A compact formulation of the model, due to Svensson (1997), is

(2) $x_{t+1} \equiv Y_{t+1}-Y_{p t+1}=-\varphi\left(i_{t}-E_{t} \pi_{t+1}\right)+\phi x_{t}+g_{t}$,

$$
\pi_{t+1}=\pi_{t}+\lambda x_{t}+u_{t+1}
$$

where $Y_{p t}$ is potential output; $x_{t}$ is the output gap; $\pi_{t+1}$ is the rate of inflation between period $t$ and period $t+1 ; E_{t} \pi_{t+1}$ is the (rational) public's forecast of this inflation given the information available to it in period $t ; i_{t}$ is the nominal rate of interest on one-period loans contracted in period $t ; u_{t+1}$ is a cost shock; $g_{t}$ is a nonmonetary shock to aggregate demand; and $\varphi, \phi$, and $\lambda$ are nonnegative parameters. Note that although there is some analogy between $x_{t}$ and $y_{t}$ from the first model, they are not identical since natural and potential output are not necessarily identical concepts. The difference between them is discussed later in this section.

In this framework, the monetary policy instrument is the nominal rate of interest. Because of price stickiness, the $\mathrm{CB}$ can affect the real rate (and through it the output gap and future inflation) by its choice of the nominal rate. Svensson (1997) notes that, in spite of its simplicity, this model captures some of the essential features of more elaborate econometric models used by some CBs. The model reflects the declared belief of some CBs, such as the $\mathrm{BE}$, that current interest rate policy affects the output gap with a lag of one period and the rate of inflation only with a lag of two periods. The model is fully backward looking in that current pricing behavior depends only on lagged variables.

\section{A New Keynesian Transmission Mechanism with Forward-Looking Pricing (Model 3)}

The main difference between this framework and the previous one is that current price setting and the current output gap depend on expectations of future inflation and on the expected future output gap, respectively, rather than on the lagged values of those variables. Thus, the model is fully forward looking. The main idea is that a change in expectations of future variables alters current pricing behavior. This modification has its origin in more explicit microeconomic foundations with monopolistic competition and costs of price adjustment. A stylized

\footnotetext{
${ }^{10}$ An additional transmission channel that is not captured by either of those models is the credit channel.

${ }^{11}$ In some versions of this model, policymakers have only imperfect control of inflation. In such a case the planned rate of inflation becomes the instrument of monetary policy.

${ }^{12}$ A fuller discussion appears in Cukierman (1992, Chap. 3).
} 
aggregate version of such a model has recently been summarized compactly by Clarida, Gali, and Gertler (1999) and is reproduced as follows:

$$
\begin{gathered}
x_{t}=-\varphi\left(i_{t}-E_{t} \pi_{t+1}\right)+E_{t} x_{t+1}+g_{t}, \\
\pi_{t}=\lambda x_{t}+\beta E_{t} \pi_{t+1}+u_{t} .
\end{gathered}
$$

Here $\varphi, \lambda$, and $\beta$ are positive coefficients. All the variables have the same meaning as in the previous model. The expected future output gap appears in the output gap equation to reflect the notion that, because individuals smooth consumption, expectations of higher consumption next period (associated with higher expected output) leads them to demand more current consumption, which raises current output.

As in stylized models of sticky staggered prices pioneered by Calvo (1983), current inflation depends on future expected inflation. In this type of model, only a fraction of firms has the opportunity to adjust its price each period and, because of costs of price adjustment, each firm adjusts its price at discrete intervals. Hence, when it is given the chance to adjust its price, the firm adjusts it by more the higher is expected future inflation. This interpretation implies that $\beta$ is a discount factor.

\section{Comparison Between the Conceptions Underlying the Different Models}

The three models above are grounded in different conceptions regarding the channels through which monetary policy affects output and inflation. In the Lucas-type model, monetary policy affects output only if it is unanticipated, either currently or when relevant nominal contracts have been concluded. Inflation in those types of models is usually thought of as being directly related to the choice of money supply via the quantity theory of money. By contrast, in the last two models, because output is demand determined, a change in the rate of interest by affecting demand also affects output independently of whether inflation is anticipated or not. Furthermore, the effect of policy on inflation in those models is through the effect that policy has on the output gap.

The main conceptual difference between the second and third models is this: In the second model, the current policy cannot affect current inflation or the current output gap; in the third model, current policy can affect the current values of both variables by changing current expectations of future variables.
Woodford (1999) utilizes this feature of the third model to show that, under an appropriate form of commitment to interest rate inertia, changes in current policy, by changing expectations, have an immediate effect on inflation and the output gap. This is a far cry from the BE view (illustrated by the second model) in which policy in year $t$ can affect inflation only from year $t+2$ onward.

\section{Haziness About the Meaning of Potential or Normal Output}

At the broad conceptual level, potential output is meant to capture long-term supply determinants of output. But there are several related concepts such as the natural level of output and the NAIRU (non-accelerating inflation rate of unemployment). At the empirical level, those concepts are often implemented by means of some statistical smoothing procedure such as the Hodrick-Prescott (1997) filter.

Are those concepts identical? I believe the answer is not necessarily. In the work of Friedman (1968) and subsequent U.S.-based neo-monetarists like Lucas $(1972,1973)$, the conception of the natural level of employment is the level of employment that is generated by the real general equilibrium of the system in the absence of inflationary surprises. Its counterpart in the United Kingdom is the NAIRU. Layard, Nickell, and Jackman (1991, pp. 14-15) characterize this rate as the rate of unemployment below which inflation is accelerating and above which it is decelerating.

Although related, the concepts developed by Lucas and Layard, Nickell, and Jackman are not necessarily identical. More importantly, both concepts generally differ from potential output because, due to the existence of real business cycles, the gap between actual and potential output may be nonzero even when inflation is fully expected and the rate of inflation is stable. As a consequence, the output gap, $x_{t}$, from neo-Keynesian frameworks is not identical to the monetarist deviation, $y_{t}$, of actual from natural output. Nor is there a clear relation between the output gap and the deviation of actual output from the NAIRU.

Woodford (2002) proposes to conceptualize potential output as the equilibrium level of output under full price flexibility and to view the output gap as arising from the existence of sticky prices. Although useful and elegant, this conception of the output gap does not provide guidance about how 
to measure the level of output under full price flexibility. It would appear that the relation between this concept and the smoothing procedures used to measure potential output in practice (such as the Hodrick-Prescott filter, 1997) is rather tenuous.

\section{Implications for Model Transparency and for Accountability}

The brief survey of alternative current models of the transmission process presented above illustrates the objective difficulties faced by the contemporary honest central banker. When faced with those and other different conceptions of how the economy works, what will he do? It is likely that he is going to intuitively assign some nonnegative weight to each of the models and to many other bits of information and ideas not surveyed here. ${ }^{13}$

What should he do when asked to be transparent about the economic model he is using to generate forecasts? This is not just an academic but also a practical question. As a matter of fact, when recently confronted with such a demand, the president of the ECB (Duisenberg) responded by promising to publish, in due time, the forecasts generated by the econometric model of the ECB. Although such an action is desirable, it is unlikely to come close to the actual aggregation of information and of models that decisionmakers at the $\mathrm{ECB}$, the $\mathrm{BE}$, or the Fed go through when making monetary policy decisions.

To a large extent, the inability of central bankers to be fully transparent about the economic model or models they are using is tied to the proliferation of alternative views of the transmission mechanism within the economic profession. Because central bankers are consumers and not providers of economic models, they obviously cannot be faulted for this state of affairs. ${ }^{14}$ But the absence of consensus about the "correct" model of the economy endows them with considerable discretion, which they can also use to hedge their positions in the face of model uncertainty and of political pressures. It also opens the door for the strategic use of information. ${ }^{15}$

Most contemporary CBs are pretty transparent about their inflation target, both in terms of the index used and the numerical target value. There is substantially less transparency about output targets. Even in countries that insist on high levels of transparency like the United Kingdom, there is quite a bit of murkiness about the output or employment target that the CB is supposed to attain.

Again, a nonnegligible part of this haziness about the output target is due to (and made possible by) the different concepts of "normal" output surveyed above. Those different conceptions allow substantial leeway for the measurement of potential or natural output, leaving room for the reintroduction of discretionary monetary policy through the back door. This is obviously the case whether or not the output target of contemporary CBs is at the natural or the potential level of output or above them. ${ }^{16}$

In the long run, transparency and accountability will be enhanced when better and more accurate models of the ways monetary policy affects the economy become available. The wider implication of this conclusion is that, until this happens, accountability by means of transparency about the economic models used by decisionmakers at the CB will be limited. What should be done in the mean time? There is no easy answer to this question. My own view is that, given the current state of economic knowledge, the discharge of accountability should be achieved to a large extent by two things: appointing as decisionmakers at the CB individuals with high levels of integrity and professional standards and making sure these decisionmakers have little or no association with particular interest groups.

\section{ARE NEW CENTRAL BANKS TRANSPARENT ABOUT THEIR OBJECTIVES?}

In comparison with past decades, there is nowadays substantially more transparency about the main objective of monetary policy. In most contem-

\footnotetext{
13 Jensen (2001) presents a compact hybrid neo-Keynesian model that combines forward- with backward-looking elements. Using a more elaborate hybrid model of the same type for the United States, Rudebusch (2001) estimates the weight on forward-looking elements to be around one-third and the weight on backward-looking elements to be around two-thirds.

${ }^{14}$ One way to bridge the gap between this proliferation of models and practical policymaking is to look for a policy rule that is uniformly best for many models. A recent attempt for two variants of microfounded structural models appears in McCallum and Nelson (1999). Hansen and Sargent (2000) develop a systematic analysis for decisionmaking when policymakers cannot distinguish between economic models within a given class.

${ }^{15}$ Reflecting on his term in office as Chairman of the Board of the Fed, Burns once said that when Keynesians on one side and monetarists on the other assailed him with diametrically opposite criticisms, he found it safe to duck in the middle.

${ }^{16}$ Staiger, Stock, and Watson (1997) show, for the United States, that there is substantial uncertainty about the location of the natural rate. Faust and Svensson (2001) show that more ex post transparency about the output target of policymakers raises social welfare.
} 
porary CBs, the main legally mandated objective of monetary policy is price stability and all other objectives are either nonexistent (as is nearly the case in the charter of the ECB) or relegated to being (at least legally) a distant second priority (as is the case with the growth and employment objectives in the charter of the BE). This is a far cry from the 1980s and previous decades during which most $\mathrm{CB}$ charters featured several conflicting objectives with no clear specification of the subjective tradeoffs among them. Nowadays all explicit inflation targeters even specify a precise numerical value in terms of a welldefined index for the target rate of inflation, and even the ECB, which is not an explicit inflation targeter, has specified a numerical inflation target for the euro area.

In spite of those advances, there still are nonnegligible dark spots about the output gap segment of the loss function of modern CBs. For truly strict inflation targeters, or inflation nutters, this murkiness is unimportant. Because the output gap is not part of their objectives, transparency about the output gap segment of their loss function is irrelevant. But practically all explicit inflation targeters openly acknowledge that they also care about the output gap, i.e., they are flexible rather than strict inflation targeters. For such banks the features of the output gap segment of the loss function and its importance relative to achieving the inflation target in each period become relevant. To illustrate, consider the following specification of the one-period CB loss function:

$$
L_{t}=A f\left(x_{t}\right)+\pi_{t}^{2}
$$

When $A=0$, the $\mathrm{CB}$ is a strict inflation targeter, so murkiness about $f\left(x_{t}\right)$ does not matter. But when $A$ is positive, the CB is a flexible inflation targeter so that murkiness about the precise form of the function $f\left(x_{t}\right)$ and the magnitude of the parameter $A$ become important. Following Svensson (1997) I will refer to $A$ as the "flexibility parameter." 17 There is little doubt that all CBs are quite opaque about the parameter $A$. This is admitted quite candidly in a recent review of the U.K. experience with inflation targeting by Vickers who notes that the MPC's remit is silent on the parameter $A$ (the full quote and source appear in the latter part of the introduction).

Ironically, the lack of transparency about $f\left(x_{t}\right)$ seems to matter the most in countries like the United Kingdom, which strongly insist on formal transparency, and the least in countries like Germany, which, judging by the BB charter, should be classi- fied as a strict inflation targeter. But the matter is not that simple. Recent empirical work by Clarida and Gertler (1997) supports the view that the Bundesbank actually conducted policy in a way that is indistinguishable from that of a flexible inflation targeter. As a matter of fact, the currently emerging consensus seems to be that, whether they admit it or not, all CBs are behaving in a manner that is consistent with flexible inflation targeting. The main difference, on this view, is only whether the bank and its charter admit the "flexible" part openly or not. In terms of the loss function in equation (6), this means that there generally is a lack of transparency with respect to the coefficient $A$.

How about $f\left(x_{t}\right)$ ? Available public information on this term is rather scant for two reasons. First, neither the CB nor the political authorities have taken the trouble to indicate what it is. Vickers (1998, p. 370) ventures several remarks on the shape of the BE's loss function since 1997 and concludes that, at least as far as inflation is concerned, losses are symmetric; but he remains silent on what the shape of $f\left(x_{t}\right)$ might be. Secondly, as discussed at some length in the previous section, there are numerous ambiguities in the definition of potential, normal, natural, and NAIRU output. Obviously the output gap that enters into the loss function inherits those ambiguities. In summary, existing CBs are generally quite opaque about their output objective, the shape of the function $f($.$) , and the flexibility of$ the parameter $A$.

\section{The Case for Asymmetries in CB Losses from the Output Gap}

In the absence of solid information about $f($.), the academic literature has assumed that $f($.) is a quadratic function implying that losses from negative and from positive output gaps are the same as long as the absolute value of the gap is the same. ${ }^{18}$ But it is hard to see why CBs, social planners, or political authorities would consider, given inflation, a positive output gap of a given magnitude to be equivalent to a negative output gap of the same magnitude. A negative output gap means that

\footnotetext{
17 Note that $A$ is the inverse of Rogoff's parameter of CB conservativeness. The terminology in the text is chosen to highlight the fact that, within the context of the present discussion, it determines the degree of flexibility in allowing temporary deviations from the inflation target.

${ }^{18}$ From here on, I abstract for simplicity from the ambiguities in the definition of the output gap and assume that the output target of monetary authorities is equal to a well-defined and publicly known measure of "potential or natural output."
} 
employment is below the normal level, whereas a positive output gap means employment is above the normal level. While casual observation suggests that policymakers dislike employment below the normal level, it does not support the notion that, given inflation, they also dislike employment above the normal level. ${ }^{19}$

Recently this casual empiricism got backing from Blinder after his resignation from the office of Vice Chairman of the Fed. Blinder expressed the view that the Fed takes far more political heat when it tightens preemptively to avoid inflation than when it eases preemptively to avoid unemployment (the precise quote and reference appear in the introduction). To the extent that the $\mathrm{CB}$ is not totally indifferent to the priorities of the political establishment, this asymmetry is likely to partially affect the Fed's policy choices. Preliminary empirical work by Gerlach (2000) and by Dolado, Maria-Dolores, and Naveira (2000) supports this hypothesis for the Fed. ${ }^{20}$

Recent theoretical work by Cukierman (2000a) shows that, with (i) a Lucas-type transmission mechanism, (ii) uncertainty about the future state of the economy, and (iii) asymmetries in the output gap segment of the CB loss function, there will be an inflation bias even if the $\mathrm{CB}$ targets the normal level of output. This framework implies that there should be a positive association between the variability of employment over the cycle and the magnitude of the inflation bias. Preliminary cross-sectional evidence in Gerlach (2000) supports this implication. Using a formulation that nests both symmetric and asymmetric losses from deviations of unemployment from its natural level, Ruge-Murcia (2001) performs a test of the asymmetry hypothesis over time within several countries and finds support for this hypothesis in France and the United States.

In summary, in spite of the silence of policymakers about the shape of $f($.), there seem to be sufficient early indications to warrant a more serious investigation of the consequences of an asymmetric $f($.). The remainder of the paper investigates the consequences of this asymmetry for the credibility of monetary policy and related issues.

\section{IS THE CREDIBILITY PROBLEM GONE WHEN THE CENTRAL BANK TARGETS THE NORMAL LEVEL OF OUTPUT?}

The discussion in this section and the next one is built on two presumptions. The first is that contemporary CBs do not attempt to maintain output above its normal or natural level, and thus there is no credibility problem because of the classical KPBG reasons. In accepting these presumptions, this section takes at face value the statements by Blinder and Vickers and also addresses McCallum's (1995, 1997) criticism of the KPBG conception of the reasons for inflation. It will be recalled that those statements and McCallum's arguments imply that the output target of central bankers is identical to the normal or potential level of output. The second presumption is that the CB loss function is more sensitive to negative than to positive output gaps. The main results of the section are as follows:

1. The presence of asymmetries in losses from the output gap in conjunction with uncertainty on the part of the $\mathrm{CB}$ about the state of the economy induces an inflation bias even when the $\mathrm{CB}$ targets potential or natural output.

2 . There is no bias when the CB is a strict inflation stabilizer $(A=0)$.

Those results hold both for a Lucas-type, expectations-augmented Phillips curve and for many other models including, in particular, a New Keynesian, sticky/staggered prices transmission mechanism of the type reviewed in Clarida, Gali, and Gertler (1999). But in the second case there is an additional inflationary tendency that arises even when decisionmakers at the $\mathrm{CB}$ are fully informed about the relevant shocks at the time policy choices are made. This section demonstrates the existence of a bias within the framework of a Lucas-type expectationsaugmented Phillips curve (model 1). The next section shows that, in addition to this bias, there is in New Keynesian economies (model 3) an additional average inflationary tendency. A third result holds true for both a Lucas-type and a New Keynesian transmission mechanism:

\footnotetext{
${ }^{19}$ Given inflation, some politicians probably even like positive output gaps on the view that the higher output is, the better it is. As a matter of fact, it is quite likely that the quadratic function on the output gap, so often used in the academic literature, was chosen mainly for analytical convenience rather than for descriptive realism. In the usual KPBG setup this assumption does not make a difference as long as policymakers do not face uncertainty or are risk neutral because the equilibrium is in the range of negative output gaps in which the quadratic is reasonable. A formulation of the KPBG framework under certainty in which the quadratic is limited to the range of negative output gaps without making any difference for their basic result appears in Cukierman (1992, Chap. 3, equation (3.1)). But once it is recognized that policymakers face uncertainty, the characteristics of their objective function in the entire range of output gaps become important.

${ }^{20}$ However, Dolado, Maria-Dolores, and Naveira (2000) do not find evidence of asymmetry in losses from the output gap for the BB, the Banque de France, or the Banco de Espana.
} 
Figure 1

The Sequence of Events
1. $E_{t-1} \pi_{t}$ is formed $\rightarrow$
2. policy, $m_{t}$, chosen $\rightarrow$
3. $\varepsilon_{t}$ realizes.

3. Other things the same, the bias is larger the larger the (inflation targeting) flexibility parameter $A$ is.

\section{An Asymmetry-Cum-Uncertainty Inflation Bias with a Lucas-Type Transmission Mechanism}

The results in this subsection draw on Cukierman (2000a). Here I briefly present the basic framework, the main result, and the intuition underlying it and move on to discuss its wider implications. (See that article for further details and some of the derivations.) The asymmetry in CB losses regarding the output gap is modeled by postulating that period $t$ 's loss function is given by

$$
L_{t}\left\{\begin{array}{c}
\frac{1}{2}\left(A x_{t}^{2}+\pi_{t}^{2}\right) \text { when } x_{t}<0 \\
\frac{1}{2} \pi_{t}^{2} \text { when } x_{t} \geq 0
\end{array}\right\} \text {, }
$$

where $x_{t} \equiv Y_{t}-Y_{p t}$ is the output gap. This specification of the loss function states that the employment target of policymakers is potential output and that as long as the output gap is negative the standard quadratic loss function is in effect. But when the output gap is positive or zero, policymakers do not incur any losses or gains. The kink at the zero output gap introduces an effect that is analogous to the condition that leads to a precautionary saving motive in the theory of savings and consumption under uncertainty. A basic result from this literature is that there is a precautionary saving motive if and only if marginal utility is convex, i.e., the third derivative is positive (Kimball, 1990). ${ }^{21}$ I shall return to the consequences of this analogy later.

The natural level of output is given by

$$
Y_{n t}=Y_{p t}+\varepsilon_{t},
$$

where $\varepsilon_{t}=Y_{n t}-Y_{p t}$ is the output gap in the absence of inflationary surprises. Actual output is given by the expectations-augmented Phillips curve in equation (1). For simplicity, $\varepsilon_{t}$ is specified as a zero-mean stochastic shock to the natural level of output with distribution function $G(\varepsilon)$. Inflation is determined both by the choice of monetary policy and by the realization of the shock, $\varepsilon_{t}$, and is given by the following equation:

$$
\pi_{t}=m_{t}-\gamma \varepsilon_{t},
$$

where $m_{t}$ is the rate of inflation planned by the CB and $\gamma$ is a positive parameter that determines the effect of shocks to employment on inflation. For concreteness I think of $\varepsilon_{t}$ as a supply shock so its effect on inflation is negative. But the basic result of this subsection goes through also when $\varepsilon_{t}$ is a demand shock so that $\gamma$ is negative or when $\varepsilon_{t}$ is a combination of supply and demand shocks. Equation (9) states that, given planned inflation, actual inflation is lower the larger the supply shock to the economy is. Provided there is no instrument uncertainty, this formulation is consistent both with situations in which the policy instrument is the interest rate as well as with situations in which it is some nominal shock.

I focus on a one-shot game with three stages. The sequence of events and the structure of information is as follows. First, expectations, $E_{t-1} \pi_{t}$, are formed and embedded into nominal contracts. In the second stage, the $C B$ picks the value of its instrument, $m_{t}$. Finally, the stochastic real shock to employment, $\varepsilon_{t}$, realizes and determines, along with monetary policy, both employment and inflation. This sequence of events is illustrated in Figure 1. A crucial element is that, when it chooses the setting of its instrument, the $\mathrm{CB}$ is uncertain about the magnitude of the real shock to output. This is a fortiori true for the public when they form their expectation.

The shock, $\varepsilon_{t}$, affects employment directly as well as indirectly by creating, given monetary policy, unanticipated inflation in a direction that is opposite to the sign of the shock. From equations (1), (8), and (9) the combined marginal impact of the shock on employment is

$$
q \equiv 1-\alpha \gamma .
$$

I assume that the direct effect of the shock on

\footnotetext{
21 The kink at zero in equation (7) implies that the marginal benefit from higher economic activity is globally convex.
} 
employment dominates its indirect effect by means of unexpected inflation so that $q$ is positive. Substituting equations (1), (8), and (9) into the loss function in equation (7), the expected value of the CB loss function is

(11)

$$
\frac{A}{2} \int_{-\infty}^{b\left(\pi^{e}-m\right)}\left[q \varepsilon+\alpha\left(m-\pi^{e}\right)\right]^{2} d G(\varepsilon)+\frac{1}{2} E_{t-1}(m-\gamma \varepsilon)^{2},
$$

where $b \equiv(\alpha / q), \pi^{e} \equiv E_{t-1} \pi_{t}$, and the time index has been suppressed for simplicity. Minimization of equation (11) with respect to $m$ yields the following reaction function for the monetary authority:

$$
\begin{aligned}
m= & \frac{1}{1+\alpha^{2} A G\left[b\left(\pi^{e}-m\right)\right]} \\
& {\left[\alpha^{2} A G\left[b\left(\pi^{e}-m\right)\right] \pi^{e}-\alpha A q \int_{-\infty}^{b\left(\pi^{e}-m\right)} \varepsilon d G(\varepsilon)\right] . }
\end{aligned}
$$

I turn next to expectation formation which occurs at the first stage of the game. Although individuals do not know the realization of $\varepsilon$ at this stage, they do know its stochastic structure as well as the structure of the economy and of $\mathrm{CB}$ objectives. Taking the expected value of inflation in equation (9) conditioned on this information as the operational proxy for the public's rational expectation of inflation, we obtain

$$
\pi^{e}=m=-\alpha A q \int_{-\infty}^{b\left(\pi^{e}-m\right)} \varepsilon d G(\varepsilon) .
$$

In equilibrium, both equations (12) and (13) must be satisfied. It follows that $\pi^{e}-m=0$ so that equation (13) becomes

(14)

$$
\begin{aligned}
E_{t-1} \pi_{t} \equiv \pi^{e} & =m \\
& =-\alpha A q \int_{-\infty}^{0} \varepsilon d G(\varepsilon)=-\alpha A q G(0) E[\varepsilon \mid \varepsilon<0] .
\end{aligned}
$$

$G(0)$ is the probability of a recession. More precisely it is the probability that the realization of the employment shock, $\varepsilon$, is lower than the mean of this shock, which is zero. $E[\varepsilon \mid \varepsilon<0]$ is the expected value of $\varepsilon$ conditioned on the economy being in a recession ( $\varepsilon$ negative). Because the probability of a recession is positive and the expected value of $\varepsilon$ conditioned on the economy being in a recession is negative, both planned and expected inflation are positive. Furthermore, in spite of its attempt to reduce the size of recessions, the $\mathrm{CB}$ has no influence on output, which remains at its natural level. Had the CB been committed to a zero rate of monetary expansion, output would still be at its natural level. Hence there is an "inflationary bias" on average.
Intuitively, this bias arises because the $\mathrm{CB}$ is more sensitive to policy errors in which monetary policy is too tight than to policy errors in which it is too expansionary, in conjunction with the fact that it does not have perfect information about the state of the economy. The upshot is that an inflationary bias arises even when the $\mathrm{CB}$ targets potential output. This bias arises whenever the $\mathrm{CB}$ is more averse to negative than to positive output gaps, in conjunction with the fact that it is uncertain about the state of the economy. The second condition is obviously highly realistic, and the first one appears to be satisfied for at least some CBs.

Although, as in KPBG, the bias arises because of the CB concern (at least in some states of nature) about the output gap, the new bias identified here does not rely on dynamic inconsistency. To see this, note that this bias is present also if the choice of policy in Figure 1 precedes the formation of expectations, as long as both the formation of expectations and the choice of policy precede the resolution of uncertainty about the shock, $\varepsilon_{t}$. The origin of the bias resides, instead, in the precautionary behavior of the CB with respect to recessions in a world of uncertainty, in conjunction with the public's awareness of this asymmetry in CB objectives. ${ }^{22}$

\section{Discussion}

The expression for the inflation bias in equation (14) implies that, other things the same, the bias is larger the larger is the variability of natural output. Gerlach (2000) presents preliminary cross-sectional evidence suggesting that there is a positive association between the average level of inflation in a country and the variance of its rate of growth. In related work Ruge-Murcia (2001) finds a positive (over time) relation between inflation and the conditional variance of unemployment in the United States and France. Given his model, this finding supports the view that policymakers in those countries are more averse to negative than to positive output gaps. Cukierman and Muscatelli (2002) find evidence of nonlinearity in interest rate reaction functions for the United States, the United Kingdom, and Japan. The pattern of these nonlinearities supports the existence of a precautionary demand for expansions in the post-1985 period in the United States.

\footnotetext{
22 Obviously, it is not easy to verify ex post whether the CB is conducting policy so as to build in a precautionary demand for expansions. As a consequence, it is not straightforward to verify a precommittment to conduct policy in a symmetric manner.
} 
As demonstrated earlier, this type of precautionary demand leads to an inflation bias.

Equation (14) also implies that the bias is an increasing function of the flexibility parameter, $A$. Hence CBs of countries that are more flexible inflation targeters have a more serious credibility problem. Because we saw earlier that transparency concerning the flexibility parameter is generally rather poor, the magnitude of this bias is generally opaque too. But, holding other things the same, it is likely to be higher in countries such as the United Kingdom than in the euro area. This is true if only because the 1997 charter of the BE explicitly mentions growth and employment as objectives for the $\mathrm{CB}$, whereas that of the ECB does not.

Those rather pessimistic conclusions appear to conflict, at first sight, with the remarkable era of price stability that Western democracies have recently experienced. The "new inflation bias story" presented here is consistent with this observation because it implies that, when the probability of recession is low and/or its expected depth mild, the bias will be negligible for most values of the flexibility parameter, $A$. But this observation should also be taken as a warning against overoptimism in the long run. In particular, if and when the likelihood of a serious recession increases, the countries of more flexible inflation targeters are likely to experience larger inflationary accelerations.

Let me conclude this discussion with a theoretical remark regarding the analogy between the behavior of policymakers in the "new inflation bias story" presented above and the theory of precautionary savings. The kink at a zero output gap in the loss function in equation (7) implies that the marginal benefit from higher economic activity is globally convex. As shown by Kimball (1990) there is a precautionary saving motive if and only if the marginal utility from consumption is convex. Similarly, asymmetric preferences with respect to the output gap induce a precautionary demand for expansions on the part of central bankers. This precautionary demand induces them to conduct a somewhat looser policy in comparison with the benchmark case of symmetric losses from the output gap. 23

But there is also a crucial difference between the two cases. While the individual consumer "buys" more desired future security by foregoing some current consumption, the central banker does not buy any improvement in economic activity because individuals in the economy undo this potential improvement by setting their nominal contracts in a way that anticipates this tendency of the central banker.

\section{THE EFFECTS OF ASYMMETRIC LOSSES FROM THE OUTPUT GAP IN NEW KEYNESIAN FRAMEWORKS}

This section investigates the consequences of an asymmetric objective function, as specified in equation (7), when the economic structure is characterized by a New Keynesian transmission mechanism with forward-looking pricing of the type given by equations (4) and (5). This section discusses two related but distinct issues. First, it shows that the presence of asymmetries in conjunction with uncertainty about future shocks produces an inflation bias also in New Keynesian frameworks. Second, it shows that, in New Keynesian frameworks, there usually is an additional inflationary tendency and an associated positive average output gap, both of which obtain even in the absence of uncertainty about future shocks. For simplicity I abstract from persistence in the stochastic behavior of the shocks $g_{t}$ and $u_{t}$ by assuming that both are zero-mean whitenoise processes.

\section{Asymmetric Output Gap Losses Produce a Bias Also in New Keynesian Frameworks}

The mechanism that produces the inflationary bias in the Lucas-type transmission mechanism depends mainly on the fact that the objective function is asymmetric in conjunction with the following: that, when choosing policy, the $\mathrm{CB}$ is uncertain about the realization of shocks at the time its policy decision is going to affect the economy. In particular, this type of mechanism will, most likely, operate within the framework of other transmission processes, including (linear) New Keynesian transmission processes, as long as the $\mathrm{CB}$ possesses the loss function in equation (7) and is uncertain about the relevant state of the economy. This intuitive argument is demonstrated rigorously in what follows. The hasty reader may just take note of equation

\footnotetext{
23 Incidentally, this analogy also implies that there will be a tendency to inflate for all asymmetric output gap loss functions in which the marginal benefit of higher economic activity is convex in the level of output. Another specification of an asymmetric output gap loss function that satisfies this requirement appears in Ruge-Murcia (2001), who specifies losses of deviations from natural unemployment as a linex function
} 
(18) and go directly to proposition 1 . Substituting equation (4) into equation (5),

$$
\begin{aligned}
\pi_{t} & =-\lambda \varphi\left(i_{t}-\pi_{t}^{e}\right)+\lambda x_{t}^{e}+\beta \pi_{t}^{e}+\lambda g_{t}+u_{t} \\
& \equiv \pi_{t}^{p}+\lambda g_{t}+u_{t}
\end{aligned}
$$

where $x_{t}^{e} \equiv E_{t} x_{t+1}, \pi_{t}^{e} \equiv E_{t} \pi_{t+1}$, and $\pi_{t}^{p}$ is the rate of inflation implicitly planned by the policymaker when he sets the interest rate at $i_{t}$. Solving out for the interest rate,

$$
i_{t}=\frac{1}{\lambda \varphi}\left(-\pi_{t}+(\lambda \varphi+\beta) \pi_{t}^{e}+\lambda x_{t}^{e}+\lambda g_{t}+u_{t}\right)
$$

Substituting equation (16) into equation (4), rearranging, and using the last expression in (15) to express actual inflation, $\pi_{t}$, in terms of its planned value, $\pi_{t}^{p}$, we obtain

$$
x_{t} \equiv Y_{t}-Y_{p t}=\frac{1}{\lambda}\left(\pi_{t}^{p}-\beta \pi_{t}^{e}+\lambda g_{t}\right),
$$

which states that, given expectations and the realization of the shock $g_{t}$, the output gap is more likely to be negative the lower the planned rate of inflation. Hence, equation (17) implies that if policymakers desire to reduce a negative output gap, they must plan a higher rate of inflation.

Consider now a $\mathrm{CB}$ whose objective is to minimize

$$
E_{0} \sum_{t=0}^{\infty} \delta^{t} L_{t}
$$

where $\delta$ is the discount factor and $L_{t}$ is given by equation (7). Because there are no endogenous state variables and no persistence in shocks, the minimization problem in equation (18) reduces to a series of one-period minimization problems and the expected values of inflation and the output gap are time invariant. I shall, therefore, omit time indices from now on. Equation (7) implies that, in each period, the form of the loss function depends on whether the output gap is negative or not. Equation (17) implies that the output gap is negative if and only if

$$
x=\frac{1}{\lambda}\left(\pi^{p}-\beta \pi^{e}+\lambda g\right)<0
$$

which is equivalent to

$$
g<\frac{1}{\lambda}\left(\beta \pi^{e}-\pi^{p}\right) \equiv g_{c}
$$

In this case the loss is given by the first line in equation (7), and otherwise it is given by the second line in that equation. Substituting (19) into equation (7) and applying the expected value operator, the typical one-period, time-invariant minimization problem is to choose $\pi^{p}$ so as to minimize the following expression:

(21)

$$
\frac{A}{2 \lambda^{2}} \int_{-\infty}^{g_{c}}\left(\pi^{p}-\beta \pi^{e}+\lambda g\right)^{2} d F[g]+\frac{1}{2} E\left(\pi^{p}+\lambda g+u\right)^{2},
$$

where $F[g]$ is the density function of $g$ and $E$ is the expected value operator. Differentiating with respect to $\pi^{p}$ and rearranging yields the following policy reaction function for the rate of inflation planned by the $\mathrm{CB}$ :

$$
\begin{aligned}
& \pi^{p} \frac{A\left\{\beta F\left[g_{c}\right] \pi^{e}-\lambda \int_{-\infty}^{g_{c}} g d F[g]\right\}}{\lambda^{2}+A F\left[g_{c}\right]} \\
& =\frac{A\left\{\beta F\left[g_{c}\right] \pi^{e}-\lambda F\left[g_{c}\right] E\left[g \mid g \leq g_{c}\right]\right\}}{\lambda^{2}+A F\left[g_{c}\right]} .
\end{aligned}
$$

Because individuals understand the modus operandi of the $\mathrm{CB}$ and have rational expectations, expected inflation, $\pi^{e}$, equals planned inflation, $\pi^{p}$. Using this and $\pi^{p}=\pi^{e}$ in equation (22) and rearranging yields

$$
\pi^{p}=\pi^{e}=\frac{-\lambda A F\left[\frac{\beta-1}{\lambda} \pi^{p}\right] E\left[g \mid g \leq \frac{\beta-1}{\lambda} \pi^{p}\right]}{\lambda^{2}+A(1-\beta) F\left[\frac{\beta-1}{\lambda} \pi^{p}\right]}
$$

This equation determines $\pi^{p}$ only implicitly because $\pi^{p}$ also appears in the argument of the distribution function $F[$.$] and in the expected value$ on the right-hand side of (23). It is nonetheless possible to establish that $\pi^{p}$ must be positive. The denominator in equation (23) is positive. Hence, the sign of planned inflation is determined by the sign of the numerator whose sign is opposite to that of the conditional expected value in the numerator. Thus, if

$$
E\left[g \mid g \leq \frac{\beta-1}{\lambda} \pi^{p}\right]<0,
$$

then $\pi^{p}$ must be positive. Because $g$ has a zero expected value, the conditional expected value,

$$
E\left[g \mid g \leq \frac{\beta-1}{\lambda} \pi^{p}\right]
$$

is negative for all possible values of $\pi^{p}$, except for the extreme case in which $\pi^{p}$ is equal to minus infinity and $\beta<1$. In this case, the right-hand side of equation (23) implies that $\pi^{p}$ is zero, which con- 
tradicts the initial assumption that $\pi^{p}$ is equal to minus infinity. Hence, only positive values of planned inflation are possible in an equilibrium with asymmetric preferences. The main conclusion is summarized in the following proposition.

Proposition 1. In the presence of asymmetric output gap objectives and CB uncertainty about future shocks to the economy, there is an inflation bias also in the New Keynesian framework.

This bias arises in spite of the fact that the $\mathrm{CB}$ does not gain anything from having a positive output gap. It arises instead, as was the case with a Lucas supply function, because of a precautionary demand for expansions by the CB. The next proposition examines the impact of the flexibility parameter, $A$, on this bias.

Proposition 2. The bias in proposition 1 is larger the larger is the flexibility parameter, $A$.

Proof: Differentiating equation (23) with respect to $A$,

$$
\frac{\partial \pi^{p}}{\partial A}=-\frac{\lambda^{3} F\left[\frac{\beta-1}{\lambda} \pi^{p}\right] E\left[g \mid g \leq \frac{\beta-1}{\lambda} \pi^{p}\right]}{\left(\lambda^{2}+A(1-\beta) F\left[\frac{\beta-1}{\lambda} \pi^{p}\right]\right)^{2}} .
$$

Because

$$
E\left[g \mid g \leq \frac{\beta-1}{\lambda} \pi^{p}\right]
$$

is negative and all the remaining terms are positive, this expression is positive. QED.

Thus, as was the case with a Lucas supply function, the bias is larger the larger is the flexibility parameter, $A$.

\section{The Additional Inflationary "Tendency" of New Keynesian Frameworks}

The previous subsection shows that the results obtained in Section IV for a Lucas supply function carry over to the New Keynesian framework. But in the case of the New Keynesian framework, there is an additional mechanism that tends to make inflation even higher. This additional inflationary tendency is directly related to the fact that, due to temporary price stickiness, the $\mathrm{CB}$ is able to alter the real rate of interest and through it the level of employment and production. This happens even when the $\mathrm{CB}$ knows future shocks to the economy with certainty. The analysis in this subsection focuses on this addi- tional inflation-creating mechanism in isolation by assuming that the CB has full information about relevant shocks at the time policy choices are made. In terms of model 3 (from Section II on the specification of models, pp. 19-20) this means that the CB knows $g_{t}$ and $u_{t}$ when it picks period $t$ 's interest rate, $i_{t}$. Because there are no endogenous state variables and future expectations are not affected by current policy, the minimization of the objective function in equation (18) is again equivalent to period-byperiod minimization.

In each period there are two possible alternative interest rate rules for the $\mathrm{CB}$. If the realization of the cost shock, $u_{t}$, is such that, given inflationary expectations, the output gap is either positive or zero when inflation is maintained at zero, the $\mathrm{CB}$ picks the rate of interest that achieves the zero inflation target. In this range the $\mathrm{CB}$ behaves as an "inflation nutter," or strict inflation targeter. If the realization of the cost shock, $u_{t}$, is such that, given inflationary expectations, the output gap is negative at a zero rate of inflation, the CB faces a tradeoff between its output and its inflation objective. Hence, given inflationary expectations, it picks the interest rate that equalizes the marginal loss from inflation to the marginal loss from a negative output gap. In this range the $\mathrm{CB}$ behaves as a flexible inflation targeter. Equations (4) and (5) imply that, at a zero inflation rate, 24

$$
\begin{aligned}
& x_{t} \geq 0 \Leftrightarrow u_{t}+\beta \pi_{t}^{e} \leq 0 \Leftrightarrow C B \text { is strict } \\
& x_{t}<0 \Leftrightarrow u_{t}+\beta \pi_{t}^{e}>0 \Leftrightarrow C B \text { is flexible. }
\end{aligned}
$$

In the first case the $\mathrm{CB}$ just picks the nominal rate of interest that achieves the zero inflation target. Equations (4) and (5) imply that in this case the interest rate rule is ${ }^{25}$

$$
i_{t}^{s}=\pi_{t}^{e}+\frac{1}{\varphi}\left[g_{t}+x_{t}^{e}+\frac{1}{\lambda}\left(u_{t}+\beta \pi_{t}^{e}\right)\right] .
$$

In the second case there is a meaningful intraperiod tradeoff between the inflation and the output gap targets. Hence, the $\mathrm{CB}$ picks the nominal interest rate so as to minimize

\footnotetext{
${ }^{24}$ Non-zero values of the demand shock, $g_{t}$, and of the expected future output gap, $x_{t}^{e}$, produce variability in both inflation and the output gap. Hence, non-zero realizations of these variables do not create a tradeoff between output and inflation variability and it pays to fully offset them. As a consequence, the sign of the output gap when inflation is maintained at zero is independent of $g_{t}$, and of the expected future output gap, $x_{t}^{e}$.

25 The superscripts $s$ and $f$ that are attached to $i_{t}$ indicate that equations (25) and (27) refer to the interest rate rules of strict and flexible inflation targeters, respectively.
} 


$$
L_{t}=\frac{1}{2}\left(A x_{t}^{2}+\pi_{t}^{2}\right)
$$

subject to equation (5). The interest rate rule that emerges in this case is given by 26

$$
i_{t}^{f}=\pi_{t}^{e}+\frac{1}{\varphi}\left[g_{t}+x_{t}^{e}+\frac{\lambda}{A+\lambda^{2}}\left(u_{t}+\beta \pi_{t}^{e}\right)\right] .
$$

Comparison of equations (25) and (27) reveals that, for the same realizations of current shocks and the same values of the expected future output gap and inflation, both the nominal and the real interest rates are lower in the second case. Furthermore, the difference between the two interest rates is larger the larger is the flexibility parameter, $A$. Using equation (25) in the expression for inflation (equation (5)), the rate of inflation in the range $u_{t}+\beta \pi_{t}^{e}>0$ is given by

$$
\pi_{t}=\frac{A}{A+\lambda^{2}}\left(u_{t}+\beta \pi_{t}^{e}\right)
$$

The rate of inflation does not respond to the demand shock or to the expected future output gap because the full offsetting of those variables improves performance on both the inflation and the output gap objectives. On the other hand, some of the cost shock and inflationary expectations are allowed to pass through to inflation because, in the case of those variables, there is a tradeoff between the inflation and the output gap objectives. Because, in the range $u_{t}+\beta \pi_{t}^{e} \leq 0$ the $\mathrm{CB}$ behaves as a strict inflation targeter, inflation in this range is always at the zero target. Using the interest rate rules for the two ranges in equation (4) and rearranging, the output gaps in the two ranges are given, respectively, by

$$
\begin{aligned}
& x_{t}^{s}=-\frac{1}{\lambda}\left(u_{t}+\beta \pi_{t}^{e}\right) \\
& x_{t}^{f}=-\frac{\lambda}{A+\lambda^{2}}\left(u_{t}+\beta \pi_{t}^{e}\right) .
\end{aligned}
$$

Thus, in the first range the output gap is always nonnegative and in the second it is always negative, but not by as much as it would have been in the absence of some output stabilization by the CB.

\section{Demonstration That Expected Inflation Is}

Positive. Because there is no persistence in shocks and no endogenous state variables, the expected value of the rate of inflation is the same for any horizon and is also the same in each period. ${ }^{27}$

Thus,

$$
E_{t-1} \pi_{t}=E_{t} \pi_{t+1}=\ldots \equiv E \pi \equiv \pi^{e},
$$

so the time index attached to the expectation can be deleted. It follows from equation (28), and from the fact that in the range $u_{t} \leq-\beta \pi_{t}^{e}$ inflation is zero, that

$$
\begin{aligned}
\pi^{e} & =\int_{-\infty}^{-\beta \pi^{e}} 0 . d F(u)+\int_{-\beta \pi^{e}}^{\infty} \frac{A}{A+\lambda^{2}}\left(u+\beta \pi^{e}\right) d F(u) \\
& =\frac{A}{A\left[1-\beta\left(1-F\left(-\beta \pi^{e}\right)\right)\right]+\lambda^{2}} \int_{-\beta \pi^{e}}^{\infty} u d F(u),
\end{aligned}
$$

where $F(u)$ is the distribution function of $u$ and where, without risk of confusion, the time index has been suppressed because the distribution of $u$ is time invariant. This expression determines the expected rate of inflation, $\pi^{e}$, but only implicitly because $\pi^{e}$ also appears on the right-hand side of the equation. It is nonetheless possible to establish that expected inflation is positive, even without an explicit solution for it. Note that $\pi^{e}=-\infty$ cannot be a solution because, for that value of $\pi^{e}$, the righthand side of the equation would be zero and the left-hand side $-\infty$. Hence, $-\beta \pi^{e}>-\infty$. Because the expected value of $u$ is zero, it follows that the integral on the extreme right-hand side of equation (31) is positive, establishing that both average and expected inflation are positive.

At first blush one may be tempted to conclude from this finding that there is an inflationary bias. But this is premature because in the present stickyprice framework the average positive rate of inflation may also be associated with a higher level of output. It is thus more accurate to refer to it as an "inflationary tendency" rather than an inflationary bias. The following subsection shows that this inflationary tendency is associated with an output gap that may be positive on average.

The Average Value of the Output Gap. As was the case with average inflation, because there is no persistence in shocks and no endogenous state variables, the expected value of the output gap is the same for any horizon and is also the same in each period. I will therefore omit the time

\footnotetext{
${ }^{26}$ Equation (27) is obtained by minimizing equation (26) with respect to $x_{t}$, using the resulting first-order condition to solve for $x_{t}$, equating this expression with equation (4), and solving for the implied nominal rate of interest, $i_{t}^{f}$.

27 Essentially the no-persistence assumption shuts off any adjustment in inflationary expectations in response to changes in exogenous economic conditions.
} 
index and just denote it by $x^{e} \equiv E x$. Using equation (29),

$$
\begin{aligned}
& x^{e} \equiv-\frac{1}{\gamma} \int_{-\infty}^{-\beta \pi^{e}}\left(u+\beta \pi^{e}\right) d F(u) \\
&-\frac{\lambda}{A+\lambda^{2}} \int_{-\beta \pi^{e}}^{\infty}\left(u+\beta \pi^{e}\right) d F(u) .
\end{aligned}
$$

Expanding and using equation (31), this expression can be shown to be equal, after some algebra, to

$$
x^{e}=\frac{1-\beta}{\lambda} \pi^{e}
$$

Thus, provided $\beta<1$ and because average inflation is positive, the average output gap is positive as well. But if $\beta=1$, the average output gap is zero. It is therefore important to have an idea about the meaning and magnitude of the parameter $\beta$. Gali and Gertler (1999, p. 207) refer to it as the subjective discount factor and provide empirical estimates suggesting that it is about two standard errors below 0.99, which is the typical value used for this parameter in the literature (op. cit. footnote 16). Hence, existing evidence is not incompatible with the possibility that $1-\beta>0$. It appears therefore that in a New Keynesian world it is possible to obtain permanent gains in output at the cost of permanently higher average inflation. This obviously violates the long-run neutrality of monetary policy and may appear surprising at first sight. To understand the deeper origin of this result, it is useful to digress and characterize the behavior of the average values of inflation and of the output gap when the CB is a strict inflation targeter in the entire range of shock realizations.

Average Inflation and Output Gaps Under a Strict Inflation Targeter as a Benchmark. In this case the flexibility parameter, $A$, is equal to zero and the interest rate rule in equation (25) applies everywhere. Inserting the condition $A=0$ into equations (31) and (33) we obtain

$$
x^{e}=\pi^{e}=0 .
$$

Thus, under a strict inflation stabilizer, expected inflation and the expected output gap are both at their zero target values. Inserting equation (34) into equation (25), the interest rate rule of a strict inflation stabilizer is

$$
i_{t}^{s}=\pi_{t}^{e}+\frac{1}{\varphi}\left[g_{t}+\frac{1}{\lambda} u_{t}\right]
$$

which implies that the expected value (as well as the average value) of the real interest rate is zero.
Implications for Degree of Flexibility in Targeting Inflation for Real Rates of Interest.

What are the implications for the average value of real rates? Is it going to be above or below the average value of the real rate under strict inflation targeting? There are two offsetting effects. On one hand, because $(1 / \lambda)>\left(\lambda /\left(A+\lambda^{2}\right)\right)$, it follows from a comparison of equations (25) and (27) that, for the same shock realizations and expectations the real rate under flexible targeting is always lower than under strict targeting in the range of negative output gaps. This effect tends to make the average value of the real rate under flexible targeting lower than under strict targeting. On the other hand, because inflationary expectations are higher under flexible targeting, a higher real rate is needed to achieve a given rate of inflation under flexible targeting than under strict targeting. This effect tends to make the real rate higher under flexible targeting. The final relation between the average level of real rates under strict versus flexible inflation targeting depends, therefore, on the relative strength of those two effects. The high real rates experienced during periods of disinflation suggest that, at least during such periods, the second effect has dominated the first one.

\section{Summary Thoughts on the Long-Run Nonneutrality of the New Keynesian Framework and the Implications for Transparency}

The analysis above suggests that, in a New Keynesian economy, a flexible inflation stabilizer with asymmetric preferences induces more inflation, on average, but also more output (at least when $\beta<1)$ than a strict inflation stabilizer. This implies that, contrary to model 1 (from Section II on the specification of models, pp. 19-20), in such an economy the $\mathrm{CB}$ faces (possibly within some restricted range of low rates of inflation) a long-run tradeoff between the average level of inflation and the average level of the output gap. ${ }^{28}$ The ability to affect output arises because, due to temporarily sticky prices, the $\mathrm{CB}$ can influence the real rate by means of the nominal rate of interest.

For a flexible inflation targeter with asymmetric

\footnotetext{
28 The qualification restricting the statement to low rates of inflation refers to the possibility that, when inflation increases beyond a certain threshold, the intervals between price adjustments become shorter. This ultimately pushes $\beta$ toward 1 and eliminates any long-run tradeoff between average inflation and the average output gap.
} 
preferences it is desirable to have a positive, rather than a zero, average rate of inflation in order to be able to reduce the magnitude of negative output gaps when such gaps occur. As a consequence, the average output gap, which was zero under a strict inflation targeter, becomes positive. It is therefore not quite appropriate to refer to the higher inflation produced by the flexible targeter as a "bias." I refer to it instead as an "inflationary tendency." Ultimately, whether the CB or society prefers more inflation and more stabilization of negative output gaps to less inflation and less stabilization of such gaps is a matter of taste.

But, to my knowledge, no CB has ever publicly acknowledged that there might be such a tradeoff. Thus, to the extent that there are at least some CBs with asymmetric preferences, they have been remarkably silent and opaque about the tradeoff between output stabilization and inflation and about their attitude to alternative values of the output gap. For example, the public stance taken by most explicit inflation targeters is that there is no relation between the degree of flexibility in targeting inflation and the average rate of inflation.

One possible reason for this position is that public acknowledgment of asymmetric attitudes to positive and negative output gaps may raise inflationary expectations and necessitate a higher average level of real rates, which CBs fear will depress the average level of output and investment. Such a fear is irrational in the models I have presented because, by the rational expectations assumption, individuals know what the true objectives of the CB are in any case. But once this extreme informational assumption is released for at least some individual price setters in the economy, it becomes rational for the CB to de-emphasize institutional factors that might raise inflationary expectations. Simon has been emphasizing cognitive and related limitations on the individual's ability to absorb information for many years. ${ }^{29}$ In the presence of such cognitive threshold effects within a sufficiently large fraction of price setters, it is rational for CBs to de-emphasize a high flexibility parameter and asymmetric preferences in order to maintain credibility.

\section{CONCLUDING REMARKS}

The main messages of the paper can be summarized as follows. First, contemporary Western CBs are rather opaque about the economic models they use in reaching policy decisions, as well as about major attributes of their objective functions. Second, although Western CBs have recently been quite precise about their inflation targets, there is substantial haziness about output targets and about the degree of flexibility allowed in targeting inflation. Third, in a world characterized by uncertainty about the future state of the economy, the shape of the loss function over the entire range of inflation and of output gaps shapes policy choices. All CBs have been remarkably silent about that. This paper makes a case for the existence of asymmetric attitudes to positive and to negative output gaps, at least for some CBs. 30

It shows, both for sticky- and for flexible-price transmission mechanisms, that in the presence of such asymmetries and uncertainty about the upcoming state of the economy there is an inflation bias even when the CB targets potential output. The reason is that such CBs are willing to tolerate some higher inflation in order to reduce the risk of unexpectedly deep recession. This precautionary demand for expansions is analogous to the precautionary saving motive in the theory of consumption under uncertainty, as generalized by Kimball (1990).

This "new inflation bias" result implies that, even if Blinder (1998), Vickers (1998), and McCallum $(1995,1997)$ are all right in believing that contemporary CBs target potential output, the risks of inflation are not gone. Although, as in KPBG, the bias arises because of the CB concern (at least in some states of nature) about the output gap, the new bias does not rely on dynamic inconsistency. The origin of the bias resides, instead, in the precautionary behavior of the $\mathrm{CB}$, with respect to recessions in a world of uncertainty, in conjunction with the public's awareness of this asymmetry in CB objectives.

Fourth, in sticky-price frameworks with forwardlooking pricing there is, within some range, a longrun tradeoff between average inflation and average output. Fifth, theory predicts that CBs with asymmetric preferences will locate at a point along this

\footnotetext{
29 A summary view with implications for economics appears in Simon (1992). A recent enlightening discussion of Simon's view for transparency in monetary policy appears in Winkler (2000).

${ }^{30}$ Casual observation suggests that most politicians definitely have asymmetric attitudes toward positive and negative output gaps. During periods of disinflation and attempted buildups of credibility, the CB may behave as if it suffers a higher loss from an upward than from a downward deviation of inflation from target. Nobay and Peel (1998) analyze the case in which both the inflation and the output gap terms in the loss function of the $\mathrm{CB}$ are asymmetric. Cukierman and Muscatelli (2002) provide a general framework and related empirical work that feature both types of asymmetries and make it possible to identify the dominant asymmetry in each country.
} 
tradeoff that is characterized by both positive average inflation and a positive output gap. This finding implies that asymmetrically inclined policymakers who believe in sticky-price models of the economy rather than in flexible-price expectations-augmented Phillips curves are inherently more inflationary. But this does not mean they have a larger bias, because their policies also bring, under sufficiently low inflation, a larger level of output.

Following conventional rational-expectations practice, the new inflation bias story presented here assumes that all agents in the economy are perfectly rational and fully aware of what central bankers are doing. Individuals familiar with the decisionmaking process within CBs may argue that most policymakers are not solving an explicit expected utility maximization problem as postulated here. Although probably true, this observation does not necessarily invalidate the relevance of the new inflation bias result. Policymakers can hedge against deeper-than-wanted recessions by means of various rules of thumb and institutional arrangements. The next paragraph provides an illustration of such a rule of thumb.

The view, currently held by some European CBs, that current monetary policy can affect inflation only in the second year after the implementation of the policy may be thought of as such a built-in institutional hedging device mainly against unexpected recessions. This device builds in a "flexible inflation targeting" hedging procedure into the policy process from the outset. The reason is that, given this belief, it would be foolish to immediately attempt to put inflation back on target following, say, a cost shock. But the belief leading to this policy prescription of flexible targeting may be disputed. Woodford (1999), for example, as well as many New Keynesians, appears to believe that monetary policy can have an immediate impact on current inflation via expected inflation. It thus is not unreasonable to believe that part of the "two-year lag" institutional belief is motivated by hedging behavior in the face of uncertainty and asymmetries in the attitudes of CBs about positive and negative output gaps.

Part of the haziness regarding objectives is understandable in view of the fact that, in New Keynesian models, inflationary expectations affect current pricing decisions. ${ }^{31}$ In particular, a flexible inflation targeter with a nonnegligible flexibility parameter has good reason to appear less flexible than he really is. This may have underlied the traditional, historical public position of the Bundesbank according to which it was not concerned about output, as well as a recent observation by Mervyn King from the Bank of England. King's argument is that it is difficult to distinguish, in practice, between strict and flexible inflation targeters because both raise interest rates when inflation and output are above target. I doubt that a strict inflation targeter would have made such a statement. As a matter of fact, CBs with asymmetric output gap concerns have, in view of the new inflation bias result presented here, a credibility reason for not highlighting this fact. By contrast, simple monetary policy games with signaling imply that a strict inflation targeter would like to send messages that would make his identity clear to the public. ${ }^{32}$ Such a "type" is unlikely to claim that it is not possible to distinguish flexible from strict inflation targeters.

Lack of transparency about objectives is probably more easily remedied than lack of transparency about economic models because the latter is largely due to lack of consensus about the true model of the economy within the economic profession. It follows that significant advances in our understanding of the channels of monetary policy are likely to substantially raise the transparency about models used and with it the accountability of CBs.

During the second part of the 1990s, many Western economies experienced remarkably low rates of inflation. Particularly striking is the experience of the United States, in which inflation was quite low in spite of the powerful and persistent expansion it went through during the last decade. Is this all due to higher $\mathrm{CB}$ independence and a stronger focus on price stability? It is likely that this is part of the explanation, but not the whole story. ${ }^{33}$

This paper suggests an additional possibility. Believing that the probability of recession is low, those banks behaved nearly as strict inflation targeters would have. This conjecture is supported by the fact that inflation was low also in countries whose CBs are flexible inflation targeters (with possibly asymmetric preferences). If correct, this conjecture also implies that, when the fears of recession

\footnotetext{
31 Jensen (2000) shows that in such cases full transparency about objectives is not necessarily desirable.

32 This is the implication of formal models of monetary policy games with private information. Two simple formulations appear in Vickers (1986) and in Cukierman (2000b).

33 Cukierman and Lippi (2001) identify an additional factor. The perma nent effects of the "new economy" in the United States were initially underestimated, leading to overestimates of the output gap and, con sequently, to more restrictive monetary policies.
} 
increase again, inflation may take off as the (currently latent) new inflationary bias of those banks comes back into being.

Finally, to maintain the paper within manageable proportions, I deliberately avoided a systematic discussion of two important questions. Is full transparency feasible, and is it always desirable? The answer to the first question is likely to be "no," as suggested by Vickers (1998) and Winkler (2000).

This still leaves open a question about whether it is desirable to extend transparency as far as the feasibility constraints would allow. The answer to this question is by no means clear cut. Recent arguments for and against doing that appear in Faust and Svensson (2001), Geraats (1999), Jensen (2000), and Cukierman (2001) and are partially summarized in the last paper. Fuller understanding of the benefits and costs of transparency must await further economic outcomes as well as academic work.

\section{REFERENCES}

Barro, Robert J. and Gordon, David B. "A Positive Theory of Monetary Policy in a Natural Rate Model." Journal of Political Economy, 1983, 91(4), pp. 589-610.

Batini, Nicoletta and Haldane, Andrew G. "Forward Looking Rules for Monetary Policy," in John B. Taylor, ed., Monetary Policy Rules. Chicago: University of Chicago Press, 1999.

Bean, Charles. “The New UK Monetary Arrangements: A View from the Literature." Unpublished manuscript, Centre for Economic Performance, LSE, January 2000.

Blinder, Alan S. Central Banking in Theory and Practice. Cambridge, MA: MIT Press, 1998.

Buiter, Willem H. "Alice in Euroland." Journal of Common Market Studies, June 1999, 37(2), pp. 181-209.

Calvo, Guillermo A. "Staggered Prices in a Utility-Maximizing Framework.” Journal of Monetary Economics, 1983, 12(3), pp. 383-98.

Clarida, Richard and Gertler, Mark. "How the Bundesbank Conducts Monetary Policy," in C.D. Romer and D.H. Romer, eds., Reducing Inflation: Motivation and Strategy. Chicago: University of Chicago Press, 1997.

; Gali, Jordi and Gertler, Mark. "The Science of Monetary Policy: A New Keynesian Perspective." Journal of Economic Literature, December 1999, 37(4), pp. 1661-707.
Cukierman, Alex. Central Bank Strategy, Credibility, and Independence: Theory and Evidence. Cambridge, MA: MIT Press, 1992.

"The Inflation Bias Result Revisited."

Unpublished manuscript, Tel-Aviv University, April 2000a. $<$ www.tau.ac.ill alexcuk/pdf/infbias $1 . p d f>$.

"Establishing a Reputation for Dependability

by Means of Inflation Targets." Economics of Governance, February 2000b, 1(1), pp. 53-76.

<www.tau.ac.i1/\% 7Ealexcuk/pdf/targt7991.pdf > .

"Accountability, Credibility, Transparency and Stabilization Policy in the Eurosystem," in Charles Wyplosz, ed., The Impact of EMU on Europe and the Developing Countries. Oxford: Oxford University Press, 2001, pp. 40-75.

and Lippi, Francesco. "Endogenous Monetary Policy with Unobserved Potential Output." Presented at the NBER November/December 2001 research conference Macroeconomic Policy in a Dynamic, Uncertain Economy. $<$ www.tau.ac.il/ alexcuk/pdf/upo-nber.pdf > .

and Muscatelli, V.A. "Asymmetric Responses in Monetary Policy: Evidence and Consequences for the Inflation Bias." Unpublished manuscript, Tel-Aviv University and University of Glasgow, February 2002. < www.tau.ac.i1/ alexcuk/pdf/cukierman-muscatelli1.pdf >

de Haan, Jakob and Eijffinger, Sylvester C.W. "The Democratic Accountability of the European Central Bank: A Comment on Two Fairy-Tales." Journal of Common Market Studies, 2000, 38(3), pp. 394-407.

Dolado, Juan J.; Maria-Dolores, Ramon and Naveira, M. "Asymmetries in Monetary Policy: Evidence for Four Central Banks.” Discussion Paper No. 2441, Centre for Economic Policy Research, April 2000.

Faust, Jon and Svensson, Lars E.O. "Transparency and Credibility: Monetary Policy with Unobservable Goals.” International Economic Review, 2001, 42(2), pp. 369-97.

Friedman, Milton. "The Role of Monetary Policy." American Economic Review, 1968, 58, pp. 1-17.

Gali, Jordi and Gertler, Mark. "Inflation Dynamics: A Structural Econometric Analysis.” Journal of Monetary Economics, 1999, 44(2), pp. 195-222. 
Geraats, Petra M. "Transparency and Reputation: Should the ECB Publish Its Inflation Forecasts?" Presented at the ECB conference Monetary Policy-Making Under Uncertainty, Frankfurt, Germany, December 1999.

Gerlach, Stefan. "Asymmetric Policy Reactions and Inflation." Unpublished manuscript, Bank for International Settlements, April 2000.

Hansen, Lars P. and Sargent, Thomas. "Wanting Robustness in Macroeconomics.” Unpublished manuscript, June 2000.

Hodrick, Robert J. and Prescott, Edward C. "Postwar U.S. Business Cycles: An Empirical Investigation.” Journal of Money, Credit, and Banking, February 1997, 29(1), pp. 1-16.

Issing, Ottmar. “The Eurosystem: Transparent and Accountable or 'Willem in Euroland'." Journal of Common Market Studies, September 1999, 37(3), pp. 503-19.

Jensen, H. "Optimal Degrees of Transparency in Monetary Policymaking." Unpublished manuscript, University of Copenhagen, August 2000.

" "Targeting Nominal Income Growth or Inflation?" Unpublished manuscript, University of Copenhagen, August 2001 (forthcoming in American Economic Review).

Kimball, Miles S. "Precautionary Saving in the Small and in the Large.” Econometrica, January 1990, 58, pp. 53-73.

King, Mervyn. "The Inflation Target Five Years On.” Bank of England Quarterly Bulletin, November 1997, 37(4), pp. 434-42.

Kydland, Finn E. and Prescott, Edward C. "Rules Rather Than Discretion: The Inconsistency of Optimal Plans.” Journal of Political Economy, 1977, 85(3), pp. 473-91.

Layard, Richard; Nickell, Stephen and Jackman, Richard. Unemployment-Macroeconomic Performance and the Labour Market. Oxford: Oxford University Press, 1991.

Lucas, Robert E. Jr. "Expectations and the Neutrality of Money." Journal of Economic Theory, 1972, 4(2), pp. 103 24.

"Some International Evidence on Output Inflation Tradeoffs." American Economic Review, 1973, 63(3), pp. 326-34.
McCallum, Bennett T. “Two Fallacies Concerning Central Bank Independence." American Economic Review Papers and Proceedings, May 1995, 85(2), pp. 207-11.

"Crucial Issues Concerning Central Bank Independence." Journal of Monetary Economics, June 1997, 39(1), pp. 99-112.

and Nelson, Edward. "Performance of Operational Policy Rules in an Estimated Semiclassical Structural Model," in John B. Taylor, ed., Monetary Policy Rules. Chicago: University of Chicago Press, 1999.

Nobay, A.R. and Peel, David A. "Optimal Monetary Policy in a Model of Asymmetric Central Bank Preferences." Unpublished manuscript, Financial Markets Group, LSE, 1998.

Rudebusch, Glenn D. "Assessing Nominal Income Rules for Monetary Policy with Model and Data Uncertainty." Unpublished manuscript, Federal Reserve Bank of San Francisco, March 2001 (forthcoming in Economic Journal and available at <www.frbsf.org/economics/economists/ grudebusch/index.html $>$ ).

Rogoff, Kenneth. "The Optimal Degree of Commitment to a Monetary Target." Quarterly Journal of Economics, November 1985, 100(4), pp. 1169-89.

Ruge-Murcia, Francisco J. "The Inflation Bias When the Central Bank Targets the Natural Rate of Unemployment." Unpublished manuscript, University of Montreal, September 2001.

Sargent, Thomas J. The Conquest of American Inflation. Princeton: Princeton University Press, 1999.

Simon, H.; Egidi, M.; Marris, R. and Viale, R. Economics, Bounded Rationality and the Cognitive Revolution. Aldershot, UK: Edward Elgar, 1992.

Staiger, Douglas; Stock, James H. and Watson, Mark W. "How Precise Are Estimates of the Natural Rate of Unemployment?" in C.D. Romer and D.H. Romer, eds., Reducing Inflation: Motivation and Strategy. Chicago: University of Chicago Press, 1997.

Svensson, Lars E.O. "Inflation Forecast Targeting: Implementing and Monitoring Inflation Targets." European Economic Review, June 1997, 41(6), pp. 1111-46.

Vickers, John. "Signalling in a Model of Monetary Policy 
with Incomplete Information." Oxford Economic Papers, November 1986, 38(3), pp. 443-55.

"Inflation Targeting in Practice: The UK

Experience." Bank of England Quarterly Bulletin, 1998, 38(4), pp. 368-75.

Winkler, Bernhard. "Which Kind of Transparency? On the Need for Clarity in Monetary Policy-Making." Working Paper No. 26, European Central Bank, August 2000.

Woodford, Michael. "Optimal Monetary Policy Inertia." Unpublished manuscript, Princeton University, 1999. $<$ www.princeton.edu/ woodford/inertia.pdf $>$.

"Interest and Prices." Unpublished manuscript, Princeton University, January 2002. < www.princeton.edul $\sim$ woodford $>$. 
